\title{
Research on Automation Design of Power Supply Scheme for Industry Expansion Based on Marking and Power distribution sharing and GIS information
}

\author{
Mao-Yi FANG, Zhi-Jie SUN, Feng XIE, Xin-Nan ZHOU', Yi-Ning NIU, \\ Jian-Wei JIA, Ya-Min SUN \\ State Grid Jibei Electric Power Co., Ltd., Research Institute, Beijing 100045, China \\ 1 jiayouzhouzhou@126.com
}

\begin{abstract}
Keywords: Industry expansion, Power Supply scheme, Marking and Power distribution sharing, Automation

Abstract. The Development of Power Supply Scheme for Industry Expansion is an important business of power supply company's external service. With the continuous improvement of electricity demand, the traditional model relying on paper files and on-site exploration has been difficult to meet the needs of users and power companies. The research of this paper is based on the results of the Marking and Power distribution sharing (PMS2.0, GIS platform, electricity collection system and so on), it will integrate the information needed for power supply scheme, establish power supply program automation and visualization model, and provide optimal decision support. This study effectively compensates for the shortcomings of manual programming and shortens the time required for industry expansion.
\end{abstract}

\section{Introduction}

Recently, streamlined management of power enterprise has been improved considerably thanks to the information development in various domains of power supply company. However, information resources cannot be smoothly shared between marketing and power distribution due to the lack of unified planning, development imbalance, etc. Power Supply Scheme for Industry Expansion is an important business of power supply company's external service. Typically, servicer need toloop up paper files or on-site exploration to conclude anappropriateaccess point. This method cannot integrate massive related information for analysis, some problems such as load imbalance and power supply crossover may occur, which could lead to poor optimization and implementation performance of the service.

This paper provides a method which takes the advantage of using visualized power grid and consumer models base on marketing and power distribution sharing (including sales and marketing information system, PMS2.0, Power grid GIS platform and electricity information acquisition system) for power supply scheme automatic design.

Power supply automatic design can help improve the rationality of power supply scheme and reduce the time consuming of industry expansion by providing opened equipment's capacity and optimized power access point. Comprehensive analysis of power quality and investment cost can also be benefited.

\section{Related Research}

\subsection{Overseas Research Status}

In developed countries such as America and Japan, smart grid has become an important strategy of the country, and the construction of smart power grids is driven by the country and enterprises, with the support of government. Smart grid strategy has become an important measure for the major developed countries to seize the high ground of future low-carbon economy. A New York power company put a power grid automation system into service which represents international highest level. It can monitor over one million power consumers simultaneously and provide power supply scheme planning with multi-dimensional automatic power source direction analysis. 
In conclusion, there are many places could be improved with comparison to the high automation level and mature concept in foreign countries. However, rather than implementing existing method, a sale and marketing automation technique should be carried out based on national conditions and domestic sale strategy.

\subsection{Domestic Research Status}

The electric marketing business provides various services to the customers through the division of labor of specific businesses in various fields, completes various business processes, and provides support for the management operation and decision-making of power supply enterprises. At the same time, through the marketing business and other business orderly cooperation, improve the whole grid enterprise information resources sharing degree. The expansion of power supply based on marketing business system appeared diverse forms, such as manually maintained power data relation. Some companies use GIS based marketing system, which makes power supply planning easier by using grid topology visualization. However, it still cannot achieve power supply planning automation due its low level information sharing capability.

At present, some provinces carried out the exploratory research of the on-site sales and marketing system which achieved some functions such as meter reading, checking, meter installation, etc. But it has some unified problems between console and applications, and its safe protection ability needs to be improved.

\section{Automation Planning of Power Supply Scheme for Industrial Expansion}

\subsection{Industry Expansion Types and Power Supply Scheme}

Industrial expansion typically includes low voltage consumer or non-resident expansion, high voltage transmission expansion, high voltage transformer installation, etc. According to the result of the on-site investigation, the power supply plan is drawn up after negotiating withthe customers about technical and economical details. The detail of the scheme are as follows:

1) Power supply request overview: name, address, power capacity, industry type, load characteristic and rating, security load capacity and customer importance rank.

2) Access scheme: power supply access point, voltage level, frequency, power capacity, wire laying mode, technical requirement, investment interface and property right demarcation point, core specific requirement of infrastructures and devices and related.

3) Electrical system scheme: user main electrical connection and operating mode, equipment capacity and electrical parameter configuration requirements, reactive power compensation configuration, emergency backup power, harmonic suppression, dispatch communication, relay protection and automation requirement, distribution station requirement; Transformer, cabinet, protection, primary and secondary equipment requirement.

4) Metering and billing scheme: metering location point setup, metering method, power information acquisition terminal installation plan, metering devices requirement; power supply type, electricity price instruction, power factor assignment method, line and transformer loss distribution method.

5) Miscellaneous: the client shall pay the business of fees and charges in accordance with the relevant provisions, the validity of power supply scheme, the responsibilities and obligations of the power supply, the power customer shall fulfil the obligations and responsibilities (including organize notes in the design, construction, completion inspection and acceptance requirements, etc.), especially after canceling a normal customer design documents review and intermediate inspection, the requirement of the customer completed inspection information, other indicate matters and follow links to deal with the matters related to inform.

\subsection{GIS Geographic Information Data system}

The industrial expansion scheme design needs to consider geographical limitations such as rivers, reservoirs, lakes, buildings, main roads, railways, highways, streets and so on. Geographic 
information data includes:

Grid status GIS information: Substation, open and closed station, distribution room, pole tower, branch box, public transformer, special transformer, special transformer and latitude and longitude of other grid equipment.

Cable channel information: cable channel starting position, cable channel terminal position;

Geographic vector information: rivers, reservoirs, lakes and buildings, the main highway, railway, highway, streets, such as geographic information vector.

\subsection{Power supply scheme design automation}

\subsubsection{Power supply scheme design}

Based on marketing and power distribution sharing, reliability, safety, economy, factors such as geographic limits, this paper mainly includes the following six steps:

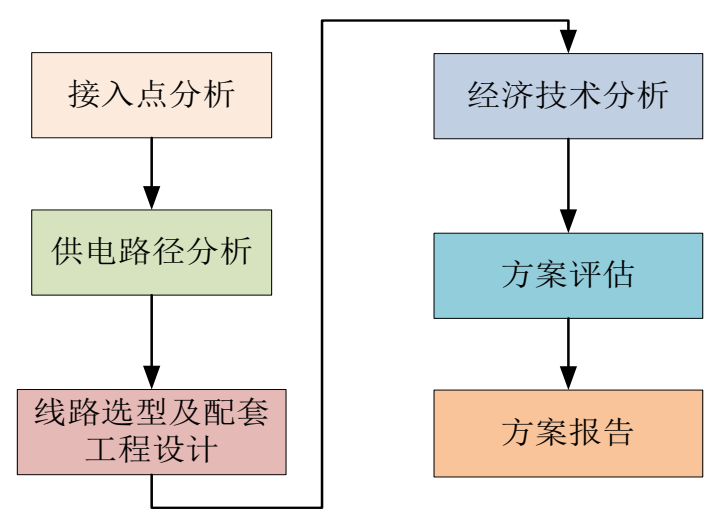

Figure1 Design flow of power supply scheme

Access point analysis: according to the urban terrain, landscape and urban road planning requirements, choose the nearest source which should be straight forward, without cross over with roads, avoiding feeding local consumer with far region source.

Route selection and engineering design: base on route, cable channel information and user reported capacity, according to DL/T5729-2016Technical guidance for distribution network planning and design.

Economic and technical analysis: according to the power supply scheme line model, the typical cost calculation method is used to calculate the project cost of the power supply scheme; The three-phase current calculation, short circuit current level analysis, voltage deviation analysis, load level analysis, network loss analysis and three-phase unbalanced calculation are carried out for the power supply scheme.

Program evaluation: the project cost, line loss, three-phase imbalance is the objective function, and the power supply plan is evaluated.

Plan selection: select the optimal scheme according to the plan evaluation result, and use the industry expansion paper template to generate the industry report.

\subsubsection{Key technologies for automation design of power supply solutions}

1) calculation of three-phase unbalanced degree

Three-phase unbalance will severely decrease stability and reliability of low voltage grid. State grid define the concept of three-phase unbalance degree in PMS2.0 as shown in equation

$$
P_{b p h}(\%)=\frac{P_{\max }-P_{\min }}{P_{\max }} \times 100 \%
$$

For consumer of 220v voltage level, three-phase unbalance problem exist in public transformer, therefore, which phase will be connected in should be considered in the power supply design auto generation process. By comparing the unbalance degree before and after installation, the proper access point could be acquired with lowest unbalance degree, as shown in the figure below. 


\section{接入相分析}

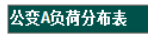

\begin{tabular}{|c|c|c|c|}
\hline 负荷 & A相 (KVA) & 相 (KVA) & C相 (KVA) \\
\hline 1 & 15 & 15 & 15 \\
\hline 2 & 8 & & \\
\hline 3 & 7 & 7 & 7 \\
\hline 4 & 6 & & \\
\hline 5 & & 9 & \\
\hline 总计 & 36 & 31 & 22 \\
\hline $\begin{array}{c}\text { 三相负荷不平衡 } \\
\text { 蓆 }\end{array}$ & \multicolumn{3}{|c|}{$39 \%$} \\
\hline \multicolumn{4}{|l|}{ 分析结果及建议 } \\
\hline 用户接入相 & A相 & 日相 & C相 \\
\hline 接入容里 & \multicolumn{3}{|c|}{$10 \mathrm{kVA}$} \\
\hline $\begin{array}{c}\text { 接入后三相不平 } \\
\text { 衡萃 }(\%)\end{array}$ & $52 \%$ & $46 \%$ & $13 \%$ \\
\hline
\end{tabular}

建议接入相: C相 -

接入后三相不平衡度：13\%

Figure 2 calculation of three-phase unbalance

2) Line loss ratio

Line loss ratio is an important index of power supply evaluation, its computation method shown as follows:

a) Branch line loss

Active power loss $p_{\text {loss }}^{i j}$ of branch ij could be expressed as:

$$
\begin{aligned}
p_{\text {loss }}^{i j} & =g_{i 0} V_{i}^{2}+g_{i j}\left[V_{i}^{2}+t_{i j}^{2} V_{j}^{2}-2 t_{i j} V_{i} V_{j} \cos \theta_{i j}\right] \\
& =g_{i 0} V_{i}^{2}+g_{i j}\left[\left(V_{i}-t_{i j} V_{j}\right)^{2}+4 t_{i j} V_{i} V_{j} \sin ^{2}\left(\theta_{i j} / 2\right)\right]
\end{aligned}
$$

In which $V_{\mathrm{i}}, V_{\mathrm{j}}$ represent node voltage of branch $\mathrm{ij}, \mathrm{kV}$

$\theta_{i j}$ — phase difference between node Iand $\mathrm{j}$, degree ;

$t_{i j}$ —if branch ij contains transformer, then ${ }^{t_{i j}}$ is the transfer ratio converted to the other side, if branch ij is a line,then $t_{i j}=1$;

$g_{i 0}$ _parallel conductance of transformer ;

$g_{i j}$ _branch conductance。

b) Line loss ratio computation

$$
\operatorname{Loss}^{i j}(\%)=\frac{p_{\text {loss }}^{i j}}{\max \left(p_{i}, p_{j}\right)} * 100 \%
$$

$p_{\text {loss _ }}^{i j}$ active power loss in branch, $\mathrm{kW}$;

$p_{i}, p_{j}$ _active power loss at node I and $\mathrm{j}, \mathrm{kW}$;

c) Asymmetry system line loss computation

There exist current in neutral line in the low voltage distribution grid, when calculating line loss, three-phase unbalance should be taken into considerations. Usually, neutral point is connected directly to ground, its power loss does really matters, and under some circumstances, neutral line could have different diameter to phase lines, which also should be taken into consideration. Typically, single phase power meter based on phase voltage $i_{p}$, phase current ${ }_{i_{p}}$ and phase $\varphi_{p}$ were used, even for three-phase meter, only the three-phase line were measured, so current in neutral line $\cdot \dot{i}_{N}$ can be calculated 


$$
\begin{aligned}
& \dot{I}_{N}=\dot{I}_{A}, \dot{I}_{B}, \dot{I}_{C} \\
& =\sqrt{I_{A}^{2}+I_{B}{ }^{2}+I_{C}{ }^{2}-2 I_{A} I_{B} \cos \left(\varphi_{A}-\varphi_{B}+\pi / 3\right)} \\
& -2 I_{B} I_{C} \cos \left(\varphi_{B}-\varphi_{C}+\pi / 3\right)-2 I_{C} I_{A} \cos \left(\varphi_{C}-\varphi_{A}+\pi / 3\right) \\
& \angle \arctan \frac{I_{A} \sin \varphi_{A}-I_{B} \sin \left(\varphi_{B}-\pi / 3\right)-I_{C} \sin \left(\pi / 3+\varphi_{C}\right)}{I_{A} \cos \varphi_{A}-I_{B} \cos \left(\varphi_{B}-\pi / 3\right)-I_{C} \cos \left(\pi / 3+\varphi_{C}\right)}
\end{aligned}
$$

Phasor of current in phase $\mathrm{N}$ is based on phase voltage, positive for lag, negative for ahead.

Take the neutral line current into the power loss equation, yield the total power loss in three-phase four-wire system

$$
\Delta P_{\text {unbalance }}=\left(I_{a}^{2}+I_{b}^{2}+I_{c}^{2}\right) \cdot R_{p}+I_{N}^{2} \cdot R_{N}
$$

3) Power supply scheme evaluation

Define the objective function of power supply scheme optimization

$$
f(x)=f\left(\alpha x_{1}+\beta x_{2}+\gamma x_{3}\right)
$$

$\alpha, \beta, \gamma$ are the weights of $x_{1}, x_{2}, x_{3}$ respectively

$\alpha, \beta, \gamma$ can be set by according to actual scenario. By choosing different $\alpha, \beta, \gamma$, optimization of various combination of price, cost and stability can be achieved.

$x_{1}$ - Total cost of construction, $x_{1}=a_{\text {线路 }}+b_{\text {杆塔 }}+c_{\text {计量装置 }}$;

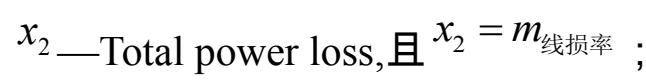

$x_{3}$ _Unbalance ratio of transformer;

$x_{3}=($ maximum phase load - minimum phase load $) /$ maximum phase load $* 100 \%$ 。

The national standard for the distribution of three-phase load imbalance should not be greater than $15 \%$, neutral line current should not be greater $25 \%$ than the transformer rated current.

Equality constraints:

$$
\left\{\begin{array}{l}
P_{g i}-P_{D i}=0 \\
Q_{g i}-Q_{D i}=0 \\
\alpha+\beta+\gamma=1
\end{array}\right.
$$

Equation (7) contains power flow constraint and weight constraint, $P_{g i}, Q_{g i}$ are injection active power and reactive power respectively at node $i$.

Inequality constraints:

$$
\begin{gathered}
\left\{\begin{array}{c}
I_{i \max } \leq I_{\max } \\
U_{i \max } \leq\left|\mu U_{N}\right| \\
S_{\mathrm{ti}} \leq 0.8 S_{n i} \\
S_{\text {sub }} \leq 0.5 S_{\mathrm{nsub}}
\end{array}\right. \\
S_{i}=S_{i \text { max }}+S_{\text {报 }}, S_{\text {sub }}=S_{\text {sub max }}+S_{\text {报 }}
\end{gathered}
$$

$I_{i \max }$ is the maximum current of the lines, which could be calculated by power flow result.

$U_{i \max }$ is the maximum voltage of the connected transformer and other related transformers (same station) which was computed from power flow result, $U_{N}$ is transformer rated voltage and $\mu$ is the voltage power quality coefficient, $\mu$ varies according to different voltage level, 220-380V, $\mu$ equals to $-10 \%-+7 \%$; higher than $35 \mathrm{kV},{ }^{\mu}$ equals to $-10 \%-+10 \%$;

$S_{\mathrm{ti}}$ represents the transformer's capacity which has been used. In case of heavy load or overload, active load should not be greater than $80 \%$ of rated capacity. 
$S_{\text {sub }}$ represents the station's capacity which has been used. In order to satisfy the N-1 safety criteria, $S_{\text {sub }}$ should be in $50 \%$ of station rated capacity.

\section{Case study}

This section provide a detailed explanation for high voltage special transformer based on aforementioned process.

1) Access point analysis

First, acquire costumers' basic information from GIS186 system, including username, address, voltage level, original capacity, capacity request and main instrument information, then locate the user on map.

Secondly, according to the location of the user map, search the power location of this high voltage special user.For the user of high-voltage special transformer, special transformer should be selected. It is a special transformer. The transformer is purchased by the user and is user's assets.Special transformer users mainly search nearby tower and cable branch box. Searching result is shown as figure 3 ;

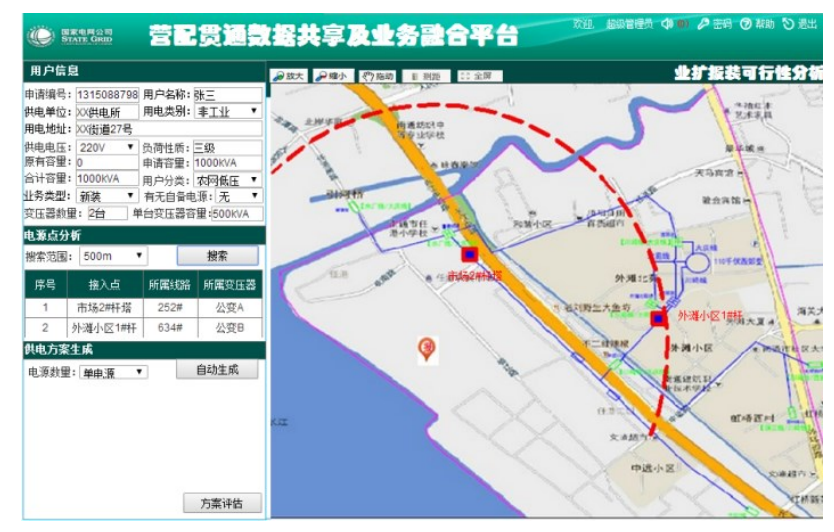

Figure 3 search result

Attention should be paid for access point analysis.

a) Voltage level belongs to tower and cable branch box should search $10 \mathrm{kV}$ first; According to DL/T 5729-2016Distribution network planning and design technical guidance, searching radius should not be greater than $3 \mathrm{~km}$ for A+,A,B type power supply area; $5 \mathrm{~km}$ for $\mathrm{C}$ type, $15 \mathrm{~km}$ for D type; For E type, searching radius should be determined by requirement. Therefore, when result cannot be generated, searching scope can be relaxed appropriately.

b) Power route analysis

Route should be generated according to location and access point, also take GIS planned route into consideration. Crossover and circuitous should be avoided. Then click the auto generation in marketing and industrial expansion system to generate detailed power supply scheme.

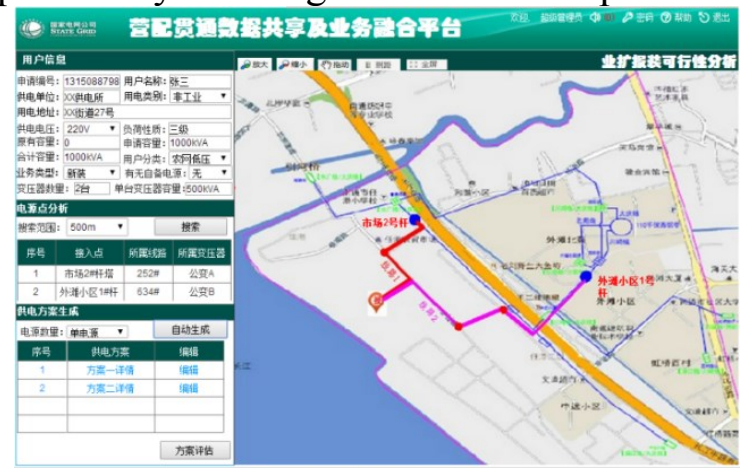

Figure 4 Power supply path 
1. Power supply scheme detail including cost analysis, phase analysis and power flow evaluation will show up by just one click.

For example according to scheme No.1, the detail of the scheme shown as follows, which includes the detail of power source, metering plan and input/output.

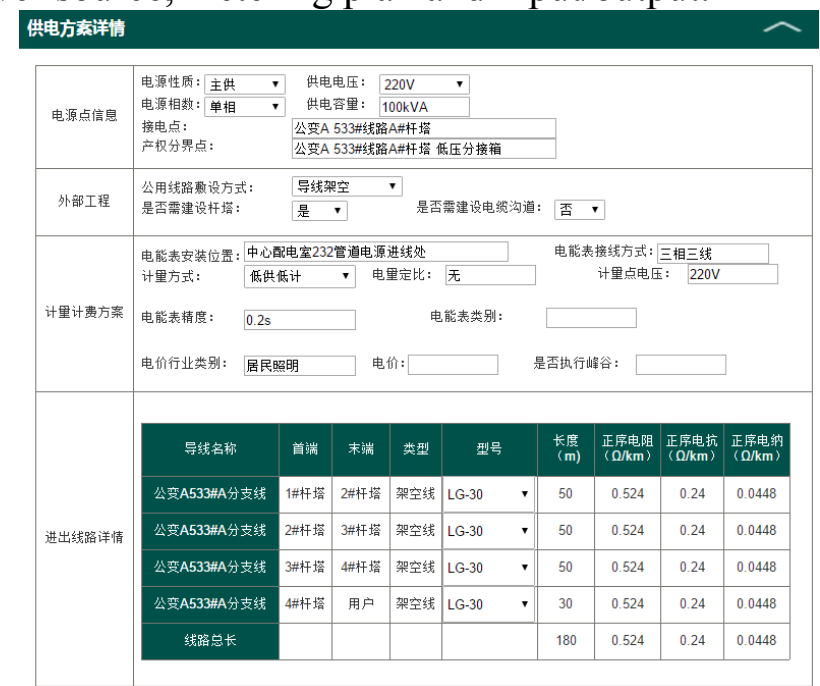

Figure5 Power supply scheme

2. Construction cost analysis: including line cost, meter charge and construction cost.

\begin{tabular}{|c|c|c|c|c|}
\hline 造价 & 数里 & 型믁 & 单价(元) & 总计 (元) \\
\hline 架空线 & $180 \mathrm{~m}$ & LG-30 & 5.3 & 954 \\
\hline 电缆 & $0 \mathrm{~m}$ & & 30 & 0 \\
\hline 计里表 & 1 & & 300 & 300 \\
\hline 电缆糗 & 0 & & 3000 & 0 \\
\hline 总计 & & & & 1254 \\
\hline
\end{tabular}

Figure 6 Cost analysis

3. Power flow analysis: Solve the power flow equations and get voltage quality pass ratio and line loss ratio.

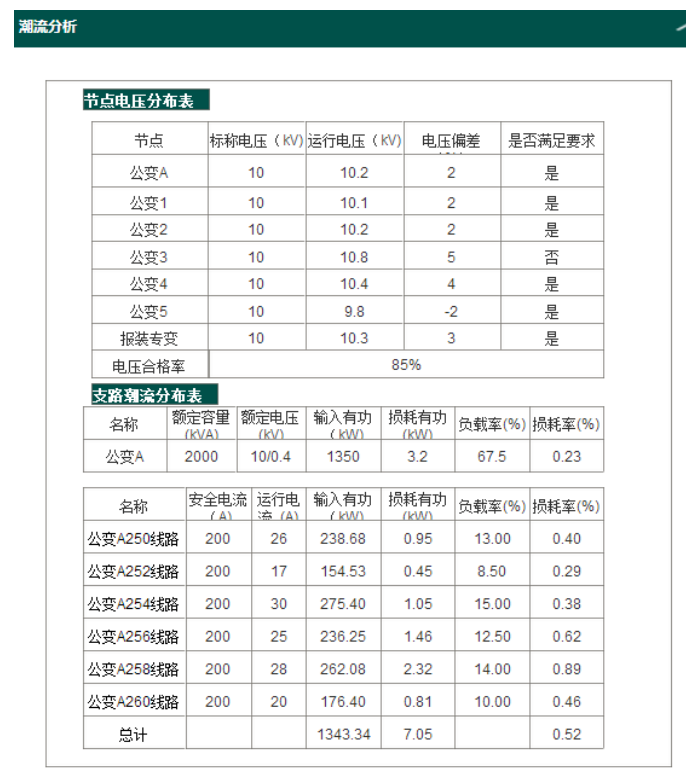

Figure7 Power flow analysis

2) Route selection and related engineering design

Cable selection should be made according to power supply route, cable channel information, 
requested capacity and DL/T 5729-2016Distribution network planning and design technical guidance.

Table 13 Recommendation form for matching of main transformer capacity with $10 \mathrm{kV}$ outlet spacing and line lead cross section

\begin{tabular}{|c|c|c|c|c|c|}
\hline \multirow[t]{2}{*}{$\begin{array}{l}110 \mathrm{kV} 35 \\
\mathrm{kV} \text { Main } \\
\text { transforme } \\
\mathrm{r} \\
\text { capacity( } \\
\text { MVA) }\end{array}$} & \multirow[t]{2}{*}{$\begin{array}{l}10 \mathrm{kV} \\
\text { Number } \\
\text { of } \\
\text { outgoing } \\
\text { lines }\end{array}$} & \multicolumn{2}{|c|}{$\begin{array}{l}\text { 10kV Main Line } \\
\text { Diameter }\left(\mathrm{mm}^{2}\right)\end{array}$} & \multicolumn{2}{|c|}{ 10kV Branch Line Diameter $\left(\mathrm{mm}^{2}\right)$} \\
\hline & & $\begin{array}{l}\text { Overhea } \\
\text { d line }\end{array}$ & Cable & $\begin{array}{l}\text { Overhead } \\
\text { line }\end{array}$ & Cable \\
\hline 80,63 & $\begin{array}{l}12 \text { and } \\
\text { more }\end{array}$ & 240,185 & 400,300 & 150,120 & 240,185 \\
\hline 50,40 & $8 \sim 14$ & $\begin{array}{c}24,185,1 \\
50\end{array}$ & $\begin{array}{c}400,300,2 \\
40\end{array}$ & $150,120,95$ & $240,185,150$ \\
\hline 31.5 & $8 \sim 12$ & 185,150 & 300,240 & 120,95 & 185,150 \\
\hline 20 & $6 \sim 8$ & 150,120 & 240,185 & 95,70 & 150,120 \\
\hline $12.5,10,6.3$ & $4 \sim 8$ & $\begin{array}{c}15,120,9 \\
5\end{array}$ & - & $95,70,50$ & - \\
\hline $3.15,2$ & $4 \sim 8$ & 95,70 & - & 50 & - \\
\hline
\end{tabular}

p.s. Typically, overhead line is ACSR, copper will be used for coastal area, overhead insulation line should be used for type A+,A,B,C area.

2. It is recommended using copper cable in the table, aluminum cable which has equivalent capacity can also be used with obeying the state standard GB50217Electrical engineering cable design specification.

3. Outgoing lines can be added for the area where the dedicated line user is more concentrated.

4. Bus should be divided when the number of outgoing lines are too large.

a) Electrical system scheme

Table 14 Receiving system scheme

\begin{tabular}{ll}
\hline Serial & Field \\
No & Access point construction type \\
2 & Access capacitance(Original 10 Request 11 Total 12) \\
3 & Main electrical wiring \\
4 & Operation mode \\
5 & Power chain mode \\
6 & Reactive power compensation(capacitance,power factor) \\
7 & Relay protection \\
8 & Dispatch, communication and automation \\
9 & Self-equipped emergency power and no-electrical security measurement \\
10 & Power quality requirement \\
\hline
\end{tabular}

b) Metering scheme

Metering point: In principle, the property rights division of power supply facilities and electrical 
facilities should be set. Power metering method: High voltage user should measure at high voltage side. However, for $10 \mathrm{kV}$, with capacity lower than $315 \mathrm{kVA}, 35 \mathrm{kV}$ with capacity lower than $500 \mathrm{kVA}$, if difficult occurs when metering at high voltage side, metering at low voltage side would be permited.

The scheme detail is shown in table 15

Table 15 Measurement scheme

\begin{tabular}{ll}
\hline Serial & Field \\
No & Metering point level \\
\hline 1 & Metering point1 name \\
3 & Metering point 1 voltage \\
4 & Metering point1metering method \\
5 & Metering point1 category \\
6 & Metering point connection Mode \\
7 & Metering location \\
8 & Meter information \\
1) & Metering device category(DL/T448) \\
$2)$ & Meter type \\
$3)$ & Metering ratio 11 \\
$4)$ & Meter connection mode \\
$5)$ & Precision level \\
$6)$ & Rated voltage \\
$7)$ & Rated current \\
$8)$ & Display type \\
9 & Price type \\
10 & Ratio \\
11 & Transformer information \\
$1)$ & Voltage transformer ratio \\
$2)$ & Voltage transformer precision level \\
$3)$ & Current transformer ratio \\
$4)$ & Current transformer precision level \\
12 & Power consumption acquiring terminal \\
$1)$ & Terminal installation status \\
$2)$ & Terminal location 14 \\
$3)$ & Terminal type 12 \\
$4)$ & Terminal amount 13 \\
\hline &
\end{tabular}

d) Price scheme 
Table 16 Price scheme

\begin{tabular}{|c|c|}
\hline Serial No & Field \\
\hline (I) & Electricity price \\
\hline 1 & $\begin{array}{l}\text { Electricity price profession } \\
\text { category }\end{array}$ \\
\hline 2 & Consumer type \\
\hline 3 & Electricity price \\
\hline 4 & Peak and valley price or not \\
\hline 5 & $\begin{array}{l}\text { Power factor assessment } \\
\text { criteria }\end{array}$ \\
\hline (II) & Service price scheme \\
\hline 1 & Service price type \\
\hline 2 & $\begin{array}{l}\text { Dual power } \\
\text { source/temporary access or } \\
\text { not }\end{array}$ \\
\hline
\end{tabular}

4) Economical and technical analysis:

Power supply scheme cost is calculated using traditional cost estimation method according to line type; Also the distribution grid power flow calculation, voltage deviation analysis, load analysis, grid loss analysis and short-circuit are investigated.

5) Scheme evaluation:

Evaluation was constrained with project cost, line loss ratio and voltage quality ratio, shown as figure 8

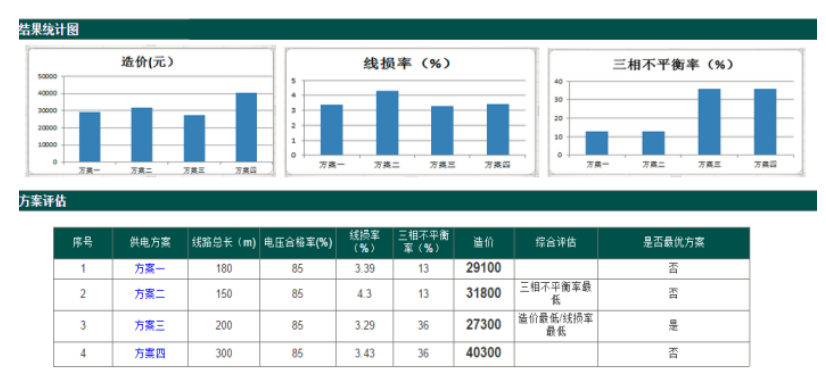

Figure 8 System design scheme

6) Scheme selection

Industry expansion report can be auto generated according to scheme evaluation optimization, including connection brief diagram.

\section{Conclusion}

This paper takes the advantage of GIS platform and marketing and distribution sharing data, provide power supply scheme design automation model with geographic, load distribution, distribution grid topology, load information and metering information integrated. This research yields a solution to the high cost, long lasting process of the traditional industry expansion, which promotes the precision level and service quality.

\section{Reference}

[1]Junzheyan ,Research on the Construction of Expert Dtabase and Expert Management, 2013.

[2]Yuangang Yao ,Xiaoyu Ma; Hui Liu;,Jin Yi,Xianghui Zhao,Lin Liu , A Semantic Knowledge Base Construction Method for Information Security, 2014.

[3]Miranda, P. ,Isaias, P.,Crisostomo, M.,, Evaluation of Expert Systems: The Application of a 
Reference Model to the Usability Parameter, 2011.

[4]Lin Feng,Guo Bao, Qian Wei, Common Elecric Power Grid GIS Platform Oriented Architecture for Electric Power Grid GIS Applications[J],Automation of Electric Power Systems.2011,35(24):68-72.

[5]Jin Liang-feng,Liu Hong-bo,Zhao Guo-bo, The Development and Application of Assistant Tool for the Business Expansion based on Gis Platform. [J].Power Demand Side Management,2015(04):52 54+57.

[6]Qi Zhi-gang,Jin Bo, Qiu Chao-ming,GIS based Optimal Design of Electric Expansion Installation and Decision-making System[J],Electric Power,2014,44(4):90-94.

[7]Li Jingbo, Guo Bin. Application of mobile operation terminal in the power supply service[J]. Power Demand Side Management, 2014,16(2):55-58.

[8]State Grid, Marketing management system and grid GIS space information service platform integration specification[S], 2010.

[9]Wang Rong, Design and application of the decision-making assistant system of power supply scheme based on GIS[J]. Power information and communication technology,2011,9(1):71-74. 